\title{
Highly Efficient Blue-Light-Emitting Diodes Based on Styrylamine Derivatives End-capped with a Diphenylvinyl Group
}

\author{
Seul Ong Kim, Kum Hee Lee, Sunwoo Kang, Jin Yong Lee, Ji Hoon Seo, ${ }^{\dagger}$ Young Kwan Kim, ${ }^{\dagger, *}$ and Seung Soo Yoon* \\ Department of Chemistry, Sungkyunkwan University, Suwon, Gyunggi-do 440-746, Korea. *E-mail: ssyoon@skku.edu \\ ${ }^{\dagger}$ Department of Information Display, Hongik University, Seoul 121-791, Korea. ${ }^{*}$ E-mail: kimyk@wow.hongik.ac.kr \\ Received November 1, 2009, Accepted December 29, 2009
}

\begin{abstract}
In this paper, we reported the synthesis and electroluminescent properties of blue fluorescent styrylamine derivatives end-capped with a diphenylvinyl group. A new series of styrylamine derivatives have been synthesized via the HornerWadsworth-Emmons reaction. To explore electroluminescent properties of these molecules, multilayer organic lightemitting devices with the configuration of ITO/NPB/1-5 doped in MADN/Bphen/Liq/Al were fabricated. All devices exhibited blue emissions with good EL performances. Among those reported herein, the device using dopant 5 exhibited a maximum luminance of $24,000 \mathrm{~cd} / \mathrm{m}^{2}$ at $11.0 \mathrm{~V}$, a luminous efficiency of $12.5 \mathrm{~cd} / \mathrm{A}$ at $20 \mathrm{~mA} / \mathrm{cm}^{2}$, a power efficiency of $6.50 \mathrm{~lm} / \mathrm{W}$ at $20 \mathrm{~mA} / \mathrm{cm}^{2}$, and $\mathrm{CIE}_{\mathrm{x}, \mathrm{y}}$ coordinates of $(\mathrm{x}=0.173, \mathrm{y}=0.306)$ at $8.0 \mathrm{~V}$, all of which demonstrate the superiority of these materials in blue OLEDs.
\end{abstract}

Key Words: OLEDs, Blue emission, Styrylamine, Diphenylvinyl group, Horner-Wadsworth-Emmons reaction

\section{Introduction}

Organic light-emitting diodes (OLEDs) have attracted a great deal of attention given their potential uses in full color flat-panel displays and lighting sources. ${ }^{1-3}$ Material development continues to play a significant role in this technology, as OLED materials have to function not only as charge transport materials but also as efficient light emitters. Recently, research has focused upon development of blue-emitting materials as the effective design of such materials with high efficiency, color purity, and long operation lifetimes is difficult due to their inherent wide energy band gaps. A variety of blue-emitting materials have been developed, ${ }^{4-7}$ however, their ultimate progression ultimately relies upon improved efficiency and color chromaticity.

The dopant/host emitter system is a common strategy in OLEDs based on small molecules. The energy transfer and charge trapping from the host to the dopant molecule allow the emission to originate from the dopant and thus, the emission properties are dominated by the dopant. Moreover, the dopant/ host system is found to enhance EL efficiency and stability of OLEDs. $^{8-11}$

Presented herein is the design and synthesis of a new class of the blue-emitting dopants (1-5) for OLEDs based on styrylamine derivatives end-capped with a diphenylvinyl group. The five different blue materials were based on a diphenylaminesubstituted styrene core structure employed to enhance lightemitting efficiency through an extended conjugated structure and improve charge transport properties through the triphenylamine moiety. In addition, an attempt was made to introduce diphenylvinyl end-capping groups into the blue compounds. Two phenyl rings as end-capping groups were forced to twist through steric hindrance and thus prevented self-quenching by molecular aggregation. In compound $\mathbf{1}$, the diphenylamine-substituted styrene emitting core and 1,1'-diphenyl group were connected directly, while other materials (2-5) have various spacer groups between the emitting core and end-capped group to test the effect of the spacer groups on performance of the blue fluorescent devices. Compounds 2, 3, 4, and 5 had phenyl, 4,4'biphenyl, 4,4',4"'-terphenyl, and 2,7-fluorenyl spacer groups, respectively. As will be seen, using these novel blue compounds as a dopant in the emitting layer, blue OLEDs with a high efficiency were demonstrated with EL performances very sensitive to the structural changes of the spacer groups in the dopants.

\section{Experimental}

Materials. All reactions were performed under a nitrogen atmosphere. Solvents were carefully dried and distilled from appropriate drying agents prior to use. Commercially available reagents were used without further purification unless otherwise stated. Both the 4-diphenylaminobenzaldehyde ${ }^{12}$ and diethyl 4diphenylaminobenzylphosphonate ${ }^{13}$ were synthesized according to literature.

${ }^{1} \mathrm{H}$ - and ${ }^{13} \mathrm{C}-\mathrm{NMR}$ spectra were recorded on a Varian (300 or Unity Inova $300 \mathrm{Nb}$ or Unity Inova $500 \mathrm{Nb}$ ) spectrometer. FT-IR spectra were recorded using a Thermo Nicolet Avatar 320 FT-IR or VERTEX 70 spectrometer. Low and high-resolution mass spectra were measured using either a Varian 4000 in EI mode, a Jeol JMS-AX505WA spectrometer in FAB mode, or a Jeol JMS-600 spectrometer in EI mode.

General procedure for synthesis of phosphonates A-D. To a solution of tetraethyl $p$-xylylenediphosphonate $(500 \mathrm{mg}, 1.32$ $\mathrm{mmol}$ ) and benzophenone ( $240 \mathrm{mg}, 1.32 \mathrm{mmol})$ in THF $(10.0$ $\mathrm{mL})$ placed in an ice bath, potassium-tert-butoxide $(1.58 \mathrm{~mL}$, $1.58 \mathrm{mmol}$ ) was added under nitrogen. The reaction mixture was stirred for $30 \mathrm{~min}$ at $0{ }^{\circ} \mathrm{C}$, followed by $1 \mathrm{~h}$ at room temperature, and quenched with water. The solution mixture was extracted twice with ethyl acetate and washed twice with water. The combined organic layers were dried over $\mathrm{MgSO}_{4}$ and the solvent removed under reduced pressure to afford a crude product that was purified through column chromatography (silica gel, hexane: ethyl acetate $=1: 1$ ) to give the desired compound. 
Diethyl 4-(2,2-diphenylvinyl)benzylphosphonate (A): Bright green oil (Yield: $35 \%)$. ${ }^{1} \mathrm{H}-\mathrm{NMR}\left(\mathrm{CDCl}_{3}, 300 \mathrm{MHz}\right): \delta 7.33-$ $7.28(\mathrm{~m}, 8 \mathrm{H}), 7.20-7.17(\mathrm{~m}, 2 \mathrm{H}), 7.06(\mathrm{dd}, J=2.3,8.3 \mathrm{~Hz}, 2 \mathrm{H})$, 6.96-6.95 (m, 3H), 4.01-3.94 (m, 4H), $3.90(\mathrm{~s}, 1 \mathrm{H}), 3.88(\mathrm{~s}, 1 \mathrm{H})$, $1.21(\mathrm{t}, J=7.0 \mathrm{~Hz}, 6 \mathrm{H}) .{ }^{13} \mathrm{C}-\mathrm{NMR}\left(\mathrm{CDCl}_{3}, 125 \mathrm{MHz}\right): \delta 143.6$, $142.8,140.6,136.3,130.6,130.3\left(\mathrm{~d}, J_{\mathrm{pc}}=9.5 \mathrm{~Hz}\right), 129.9(\mathrm{~d}$, $\left.J_{\mathrm{pc}}=3.2 \mathrm{~Hz}\right), 129.6\left(\mathrm{~d}, J_{\mathrm{pc}}=6.6 \mathrm{~Hz}\right), 128.8,128.4,128.0$, $127.8,127.73,127.6,62.3\left(\mathrm{~d}, J_{\mathrm{pc}}=6.7 \mathrm{~Hz}\right), 33.8\left(\mathrm{~d}, J_{\mathrm{pc}}=138.0\right.$ $\mathrm{Hz}), 16.6\left(\mathrm{~d}, J_{\mathrm{pc}}=6.0 \mathrm{~Hz}\right)$. FT-IR [KBr]: 3053, 3023, 2981, 2906, 1510, 1443, 1248, 1053, 1026, 963, 850, 762, 699. EI-MS $(\mathrm{m} / \mathrm{z}): 407\left[\mathrm{M}^{+}\right]$. HRMS [EI $\left.{ }^{+}\right]$calcd for $\mathrm{C}_{25} \mathrm{H}_{28} \mathrm{ON}$ : 407.1776. Found: 407.1781.

Diethyl (4'-(2,2-diphenylvinyl)biphenyl-4-yl)methylphosphonate (B): Greenish oil (Yield: $37 \%) .{ }^{1} \mathrm{H}-\mathrm{NMR}\left(\mathrm{CDCl}_{3}, 300\right.$ $\mathrm{MHz}): \delta 7.50(\mathrm{~d}, J=7.7 \mathrm{~Hz}, 2 \mathrm{H}), 7.38-7.27$ (m, 12H), 7.26-7.23 $(\mathrm{m}, 2 \mathrm{H}), 7.08(\mathrm{~d}, J=8.3 \mathrm{~Hz}, 2 \mathrm{H}), 7.00(\mathrm{~s}, 1 \mathrm{H}), 4.07-3.98(\mathrm{~m}$, $4 \mathrm{H}), 3.20(\mathrm{~s}, 1 \mathrm{H}), 3.12(\mathrm{~s}, 1 \mathrm{H}), 1.25(\mathrm{t}, J=7.0 \mathrm{~Hz}, 6 \mathrm{H}) .{ }^{13} \mathrm{C}-\mathrm{NMR}$ $\left(\mathrm{CDCl}_{3}, 125 \mathrm{MHz}\right): \delta 143.6,143.0,140.7,139.4,139.0,136.7$, $130.9\left(\mathrm{~d}, J_{\mathrm{pc}}=9.3 \mathrm{~Hz}\right), 130.6,130.4\left(\mathrm{~d}, J_{\mathrm{pc}}=6.6 \mathrm{~Hz}\right), 130.2$, $129.0,128.5,128.0,127.9,127.8,127.7,127.2\left(\mathrm{~d}, J_{\mathrm{pc}}=3.1\right.$ $\mathrm{Hz}), 126.7,62.4\left(\mathrm{~d}, J_{\mathrm{pc}}=6.7 \mathrm{~Hz}\right), 33.7\left(\mathrm{~d}, J_{\mathrm{pc}}=8.1 \mathrm{~Hz}\right), 16.7$ $\left(\mathrm{d}, J_{\mathrm{pc}}=6.0 \mathrm{~Hz}\right)$. FT-IR $[\mathrm{KBr}]: 3025,2983,2916,2849,1495$,

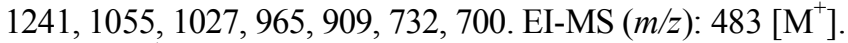
HRMS [EI ${ }^{+}$calcd for $\mathrm{C}_{31} \mathrm{H}_{32} \mathrm{O}_{3} \mathrm{P}: 483.2089$. Found: 483.2076.

Diethyl (4"-(2,2-diphenylvinyl)-p-terphenyl-4-yl)methylphosphonate (C): White solid (Yield: $36 \%) .{ }^{1} \mathrm{H}-\mathrm{NMR}\left(\mathrm{CDCl}_{3}\right.$, $300 \mathrm{MHz}): \delta 7.62$ (s, 4H), $7.58(\mathrm{~d}, J=7.7 \mathrm{~Hz}, 2 \mathrm{H}), 7.43$ (d, $J=$ $8.4 \mathrm{~Hz}, 2 \mathrm{H}), 7.39-7.30(\mathrm{~m}, 10 \mathrm{H}), 7.28-7.24(\mathrm{~m}, 2 \mathrm{H}), 7.10(\mathrm{~d}, J=$ $8.4 \mathrm{~Hz}, 2 \mathrm{H}), 7.01$ (s, 1H), 4.07-4.02 (m, 4H), $3.23(\mathrm{~s}, 1 \mathrm{H}), 3.16$ $(\mathrm{s}, 1 \mathrm{H}), 1.27$ (t, $J=7.1 \mathrm{~Hz}, 6 \mathrm{H}) .{ }^{13} \mathrm{C}-\mathrm{NMR}\left(\mathrm{CDCl}_{3}, 125 \mathrm{MHz}\right)$ : $\delta 143.6,143.0,140.7,139.8,139.4,139.5,139.0,136.8,131.0$ $\left(\mathrm{d}, J_{\mathrm{pc}}=9.3 \mathrm{~Hz}\right), 130.6,130.5\left(\mathrm{~d}, J_{\mathrm{pc}}=6.6 \mathrm{~Hz}\right), 130.3,129.0$, $128.5,127.9,127.8,127.8,127.7,127.5,127.4,127.3\left(\mathrm{~d}, J_{\mathrm{pc}}=\right.$ $3.0 \mathrm{~Hz}), 126.7,62.4\left(\mathrm{~d}, J_{\mathrm{pc}}=6.8 \mathrm{~Hz}\right), 33.7\left(\mathrm{~d}, J_{\mathrm{pc}}=138.20 \mathrm{~Hz}\right)$, $16.6\left(\mathrm{~d}, J_{\mathrm{pc}}=6.0 \mathrm{~Hz}\right)$. FT-IR [KBr]: 3026, 2981, 2916, 1491, 1248, 1054, 1026, 962, 818, 771, 732, 700. EI-MS (m/z): 559 $\left[\mathrm{M}^{+}\right]$. HRMS $\left[\mathrm{EI}^{+}\right]$calcd for $\mathrm{C}_{37} \mathrm{H}_{36} \mathrm{O}_{3} \mathrm{P}: 559.2402$. Found: 559.2416.

Diethyl (7-(2,2-diphenylvinyl)-9,9-diethylfluoren-2-yl)methylphosphonate (D): Green solid (Yield: $36 \%$ ). ${ }^{1} \mathrm{H}-\mathrm{NMR}$ (CD$\left.\mathrm{Cl}_{3}, 300 \mathrm{MHz}\right): \delta 7.56(\mathrm{~d}, J=7.7 \mathrm{~Hz}, 1 \mathrm{H}), 7.50(\mathrm{~d}, J=7.9 \mathrm{~Hz}$, 1H), 7.39-7.28 (m, 8H), 7.26-7.19 (m, 4H), 7.12 (dd, $J=1.2 \mathrm{~Hz}$, $7.4 \mathrm{~Hz}, 1 \mathrm{H}), 7.08(\mathrm{~s}, 1 \mathrm{H}), 6.78(\mathrm{~s}, 1 \mathrm{H}), 4.05-3.93(\mathrm{~m}, 4 \mathrm{H}), 3.24$ $(\mathrm{s}, 1 \mathrm{H}), 3.17(\mathrm{~s}, 1 \mathrm{H}), 1.86-1.59(\mathrm{~m}, 4 \mathrm{H}), 1.21(\mathrm{t}, J=7.1 \mathrm{~Hz}, 6 \mathrm{H})$, $0.17(\mathrm{t}, J=7.3 \mathrm{~Hz}, 6 \mathrm{H}) .{ }^{13} \mathrm{C}-\mathrm{NMR}\left(\mathrm{CDCl}_{3}, 125 \mathrm{MHz}\right): \delta 150.9$, $149.4,143.6,142.4,141.0,140.4\left(\mathrm{~d}, J_{\mathrm{pc}}=3.8 \mathrm{~Hz}\right), 140.2(\mathrm{~d}$, $\left.J_{\mathrm{pc}}=1.5 \mathrm{~Hz}\right), 136.6,130.7,130.4\left(\mathrm{~d}, J_{\mathrm{pc}}=9.6 \mathrm{~Hz}\right), 129.3,129.0$, $128.9,128.7\left(\mathrm{~d}, J_{\mathrm{pc}}=6.8 \mathrm{~Hz}\right), 128.5,127.8,127.7,127.5,124.6$ $\left(\mathrm{d}, J_{\mathrm{pc}}=6.6 \mathrm{~Hz}\right), 123.9,119.9,119.3,62.4\left(\mathrm{~d}, J_{\mathrm{pc}}=6.8 \mathrm{~Hz}\right)$, $55.9,34.4\left(\mathrm{~d}, J_{\mathrm{pc}}=137.72 \mathrm{~Hz}\right), 32.7,16.6\left(\mathrm{~d}, J_{\mathrm{pc}}=6.0 \mathrm{~Hz}\right), 8.7$. FT-IR [KBr]: 3023, 2965, 2919, 2851, 1491, 1465, 1445, 1242, 1055, 1029, 967, 908, 824, 734, 700. EI-MS (m/z): $551\left[\mathrm{M}^{+}\right]$. HRMS [EI ${ }^{+}$calcd for $\mathrm{C}_{36} \mathrm{H}_{40} \mathrm{O}_{3} \mathrm{P}: 551.2715$. Found: 551.2720.

General procedure for synthesis of blue compounds 1-5. To a stirred solution of diethyl 4-(diphenylamino)benzylphosphonate (500 mg, $1.64 \mathrm{mmol}$ ) and benzophenone (449 mg, 1.64 $\mathrm{mmol})$ in anhydrous THF $(10.0 \mathrm{~mL})$ at $0{ }^{\circ} \mathrm{C}$ was added dropwise, potassium tert-butoxide $(1.97 \mathrm{~mL}, 1.97 \mathrm{mmol})$. The mixture was stirred at $0{ }^{\circ} \mathrm{C}$ for $20 \mathrm{~min}$. The solution was allowed to warm to room temperature and stirred for $2 \mathrm{~h}$ before $\mathrm{H}_{2} \mathrm{O}$ was added. The solution was extracted twice with $\mathrm{CH}_{2} \mathrm{Cl}_{2}$. The combined organic layers were washed with brine and $\mathrm{MgSO}_{4}$. After filtration and evaporation of the solvent, the crude product was purified by column chromatography (silica gel, hexane:ethyl acetate $=10: 1)$ and recrystallized from $\mathrm{CH}_{2} \mathrm{Cl}_{2} / \mathrm{EtOH}$ to give the desired compound.

4-(2,2-diphenylvinyl)- $\mathbf{N}, \boldsymbol{N}$-diphenylaniline (1): Bright green solid (Yield: $60 \%) .{ }^{1} \mathrm{H}-\mathrm{NMR}\left(\mathrm{CDCl}_{3}, 300 \mathrm{MHz}\right): \delta 7.38-7.29$ $(\mathrm{m}, 7 \mathrm{H}), 7.27-7.19(\mathrm{~m}, 7 \mathrm{H}), 7.07-6.97(\mathrm{~m}, 6 \mathrm{H}), 6.91(\mathrm{~s}, 1 \mathrm{H})$, 6.89-6.79 (m, 4H). ${ }^{13} \mathrm{C}-\mathrm{NMR}\left(\mathrm{CDCl}_{3}, 125 \mathrm{MHz}\right): \delta 147.7,146.7$, 143.8, 143.6, 141.0, 131.5, 130.6, 130.5, 129.5, 129.0, 128.4, 127.9, 127.6, 127.4, 124.9, 123.3, 122.7; FT-IR [KBr]: 3056, 3026, 1589, 1490, 1328, 1277, 908, 757, 732, 697. EI-MS ( $\mathrm{m} / \mathrm{z})$ : $423\left[\mathrm{M}^{+}\right]$. HRMS $\left[\mathrm{EI}^{+}\right]$calcd for $\mathrm{C}_{32} \mathrm{H}_{25} \mathrm{~N}: 423.2989$. Found: 423.2987 .

4-(4-(2,2-diphenylvinyl)styryl)- $\mathbf{N}, \mathbf{N}$-diphenylaniline (2): Yellow solid (Yield: $40 \%) .{ }^{1} \mathrm{H}-\mathrm{NMR}\left(\mathrm{CDCl}_{3}, 300 \mathrm{MHz}\right): \delta$ 7.37-7.31 (m, 10H), 7.29-7.22 (m, 9H), 7.16-7.07 (m, 4H), 7.05-6.96 (m, 7H), $6.91(\mathrm{~s}, 1 \mathrm{H}) .{ }^{13} \mathrm{C}-\mathrm{NMR}\left(\mathrm{CDCl}_{3}, 125 \mathrm{MHz}\right)$ : $\delta 147.76,147.58,143.66,142.63,140.74,136.71,136.31,131.73$, $130.64,130.14,129.54,129.01,128.48,128.28,128.13,127.83$, $127.76,127.75,127.57,126.83,126.17,124.76,123.77,123.30$. FT-IR [KBr]: 3055, 3025, 1589, 1509, 1450, 1329, 1278, 962 , 908, 830, 757, 732, 698. EI-MS ( $m / z): 525\left[\mathrm{M}^{+}\right]$. HRMS [EI $\left.{ }^{+}\right]$ calcd for $\mathrm{C}_{40} \mathrm{H}_{31} \mathrm{~N}$ : 525.2449. Found: 525.2457.

4-(2-(4'-(2,2-diphenylvinyl)biphenyl-4-yl)vinyl)- $\mathrm{N}, \mathrm{N}$-diphenylaniline (3): Green solid (Yield: 64\%). ${ }^{1} \mathrm{H}-\mathrm{NMR}\left(\mathrm{CDCl}_{3}\right.$, $300 \mathrm{MHz}): \delta 7.53(\mathrm{~d}, J=1.8 \mathrm{~Hz}, 4 \mathrm{H}), 7.42-7.32(\mathrm{~m}, 11 \mathrm{H})$, 7.30-7.23 (m, 6H), 7.13-7.00 (m, 14H). ${ }^{13} \mathrm{C}-\mathrm{NMR}\left(\mathrm{CDCl}_{3}, 125\right.$ $\mathrm{MHz}): \delta 147.8,147.6,143.6,142.9,140.7,139.5,139.0,136.9$, $136.7,131.717,130.637,130.3,129.6,129.0,128.5,128.3$, $128.0,127.9,127.8,127.7,127.6,127.2,127.0,126.7,126.5$, 124.8, 123.8, 123.3. FT-IR [KBr]: 3025, 1589, 1491, 1329, $1279,907,824,757,732,698$. EI-MS $(\mathrm{m} / \mathrm{z}): 601\left[\mathrm{M}^{+}\right]$. HRMS $\left[\mathrm{EI}^{+}\right]$calcd for $\mathrm{C}_{46} \mathrm{H}_{35} \mathrm{~N}$ : 601.2766. Found: 601.2769.

4-(2-(4”-(2,2-diphenylvinyl)-p-terphenyl-4-yl)vinyl)- $N, N$ diphenylaniline (4): Yellow solid (Yield: 84\%). ${ }^{1} \mathrm{H}-\mathrm{NMR}$ (CD$\left.\mathrm{Cl}_{3}, 300 \mathrm{MHz}\right): \delta$ 7.68-7.55 (m, 8H), 7.45-7.39 (m, 3H), 7.38$7.33(\mathrm{~m}, 6 \mathrm{H}), 7.31-7.24(\mathrm{~m}, 10 \mathrm{H}), 7.13-7.00(\mathrm{~m}, 12 \mathrm{H}) .{ }^{13} \mathrm{C}-\mathrm{NMR}$ $\left(\mathrm{CDCl}_{3}, 125 \mathrm{MHz}\right): \delta 147.8,147.7,144.3,143.7,143.0,140.7$, 139.8, 139.6, 139.0, 137.1, 136.8, 131.8, 130.6, 130.3, 129.5, 129.0, 128.6, 128.5, 127.9, 127.8, 127.7, 127.6, 127.4, 127.3, 127.0, 126.8, 126.7, 124.8, 123.8, 123.3. FT-IR [KBr]: 3026, $1588,1490,1329,1279,907,819,755,732,697$. EI-MS $(\mathrm{m} / z)$ : $677\left[\mathrm{M}^{+}\right]$. HRMS $\left[\mathrm{EI}^{+}\right]$calcd for $\mathrm{C}_{52} \mathrm{H}_{39} \mathrm{~N}$ : 607.3076 . Found: 607.3082 .

4-(2-(7-(2,2-diphenylvinyl)-9,9-diethylfluoren-2-yl)vinyl)$\mathbf{N}, \mathbf{N}$-diphenylaniline (5): Green solid (Yield: 64\%). ${ }^{1} \mathrm{H}-\mathrm{NMR}$ $\left(\mathrm{CDCl}_{3}, 300 \mathrm{MHz}\right): \delta 7.59(\mathrm{~d}, J=7.9 \mathrm{~Hz}, 1 \mathrm{H}), 7.55(\mathrm{~d}, J=7.9$ $\mathrm{Hz}, 1 \mathrm{H}), 7.44-7.22$ (m, 17H), 7.16-7.01 (m, 13H), $6.79(\mathrm{~s}, 1 \mathrm{H})$, 1.90-1.60 (m, 4H), $0.22(\mathrm{t}, J=7.3 \mathrm{~Hz}, 6 \mathrm{H}) .{ }^{13} \mathrm{C}-\mathrm{NMR}\left(\mathrm{CDCl}_{3}\right.$, $125 \mathrm{MHz}): \delta 151.1,149.8,147.9,147.5,143.7,142.4,141.1$, $140.3,136.8,136.5,132.1,130.7,129.5,129.4,129.0,128.9$, $128.5,128.0,127.8,127.7,127.6,127.5,125.8,124.8,123.9$, $123.8,123.23,120.7,120.0,119.3,55.9,32.8,8.8$. FT-IR [KBr]: 3056, 3025, 2963, 2920, 1589, 1491, 1464, 1329, 1279, 962, 
907, 822, 733, 698. EI-MS (m/z): 669 [M ${ }^{+}$]. HRMS [EI $\left.{ }^{+}\right]$calcd for $\mathrm{C}_{51} \mathrm{H}_{43} \mathrm{~N}$ : 669.3393. Found: 669.3396 .

Photophysical measurements. The UV-vis absorption measurements of these newly designed compounds in dichloromethane $\left(10^{-5} \mathrm{M}\right)$ were acquired with a Sinco S-3100 in a quartz cuvette $(1.0 \mathrm{~cm}$ path). Photoluminescence spectra were measured on an Amincobrowman series 2 luminescence spectrometer. Fluorescence quantum yields of the emitting materials were determined in dichloromethane at $293 \mathrm{~K}$ against 4,4'-bis[4(diphenyl-amino)styryl]biphenyl (BDAVBi) as a reference $(\Phi=$ $0.86){ }^{14}$

HOMO (highest occupied molecular orbital) energy levels were determined with a low energy photoelectron spectrometer (Riken-Keiki, AC-2). The energy band gaps were determined from the intersection of the absorption and photoluminescence spectra. LUMO (lowest unoccupied molecular orbital) energy levels were calculated by subtracting the corresponding optical band gap energies from the HOMO energy values.

OLED fabrication and characterization. For fabricating OLEDs, indium-tin-oxide (ITO) thin films coated on glass substrates were used, which were $30 \Omega$ /square of the sheet resistivity at a $1000 \AA$ thickness. The ITO-coated glass was cleaned in an ultrasonic bath by the following sequences: acetone, methyl alcohol, distilled water, storage in isopropyl alcohol for $48 \mathrm{~h}$, drying by an $\mathrm{N}_{2}$ gas gun. The substrates were treated by $\mathrm{O}_{2}$ plasma treatment at $2 \times 10^{-2}$ Torr at $125 \mathrm{~W}$ for $2 \mathrm{~min}$. All organic materials and metals were deposited under high vacuum $(5 \times$ $10^{-7}$ Torr). The OLEDs fabricated in this paper had a configuration of indium tin oxide (ITO)/4,4'-bis[ $N$-(1-naphthyl)- $N$-phenylamino]biphenyl (NPB) (500 A)/2-methyl-9,10-di(2-naphthyl)anthracene (MADN): Blue dopants 1-5 (300 A)/4,7-diphenyl-1,10-phenanthroline (Bphen) (300 $\AA$ )/lithium quinolate (Liq) $(20 \AA) / \mathrm{Al}(1000 \AA)$. NPB was used as the hole-transporting material with Bphen as the electron-transporting material. The current density (J), luminance (L), luminous efficiency (LE), power efficiency (PE), and CIE chromaticity coordinates of the OLEDs were measured with a Keithly 2400, Chroma meter CS1000A. Electroluminance was measured using a Roper Scientific Pro 300i.

\section{Results and Discussion}

Scheme 1 shows targeted compounds $\mathbf{1 - 5}$. These styrylamine derivatives were prepared within two steps from commercially available reagents and reported previously materials. The synthetic routes of the new styrylamine derivatives used in this study are shown in Scheme 2. To investigate the influence of the spacer groups, five designed compounds introduced four spacer groups with various aromatic units. Blue compounds 1-5 were synthesized by Horner-Wadsworth-Emmons reactions between corresponding phosphonate and carbonyl compound with moderate yields. ${ }^{15}$ The molecular structures of the compounds were characterized by ${ }^{1} \mathrm{H}$ - and ${ }^{13} \mathrm{C}-\mathrm{NMR}$, FT-IR, and low- and high-resolution mass spectroscopy. High-pressure liquid chromatography (HPLC) analysis was carried out to establish purity of the blue-emitting materials (1-5) as at least above $99.0 \%$.

UV-vis absorption and photoluminescence spectra of compounds 1-5 in dichloromethane are shown in Fig. 1. In the UVvis spectra, the maximum absorption peaks of compounds 1-5 were located at 365, 393, 388, 384, and $399 \mathrm{~nm}$, respectively; the photoluminescence peaks of compounds $\mathbf{1 - 5}$ were at 472 , 496, 490, 482, and $482 \mathrm{~nm}$, respectively. A summary of photophysical properties of these materials is given in Table 1 . The absorptions that fall within $\lambda_{\max }=300-399 \mathrm{~nm}$ are attributed to $\mathrm{n} \rightarrow \pi^{*}$ and $\pi \rightarrow \pi^{*}$ transitions. According to the data given in Table 1 and Fig. 1, the introduction of various aromatic spacer groups shows a bathochromic effect on their fluorescent emissions. Compared to the PL spectrum of 1, spectra of 2-5 showed red shifts from 10 to $24 \mathrm{~nm}$ due to the increase in $\pi$-conjugation length by the spacer groups. Interestingly, blue shifts were observed in the fluorescence spectra of compounds $\mathbf{3}$ and $\mathbf{4}$ with conjugation lengths longer than compound $\mathbf{2}$. Compound $\mathbf{2}$ had a nearly planar structure that assured a large conjugation system, which in turn provided a pathway for efficient intermolecular interactions. Compound $\mathbf{3}$ and $\mathbf{4}$ broke the conjugation system due to the distorted structure at the inner biphenyl and terphenyl units, in comparison with the linear geometry of compound 2. Consequently, the energy gaps of compounds $\mathbf{3}$ and $\mathbf{4}$ increased while the absorption/emission peaks were blue-shifted in comparison with compound 2. Particularly, absorption spectra of compounds 2-5 showed a favorable overlap with the emission of a common blue host (MADN), respectively, indicating that MADN served well as a host in OLED devices using materials 2-5 as dopants.

The quantum yields of compounds $\mathbf{1 - 5}$ are given in Table 1 . The fluorescence quantum yield of compounds 1-5 in $\mathrm{CH}_{2} \mathrm{Cl}_{2}$

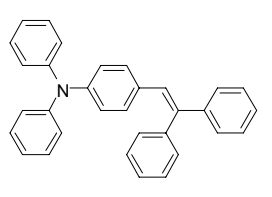

1

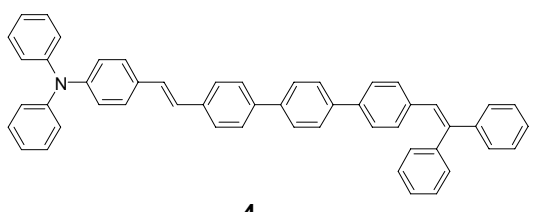

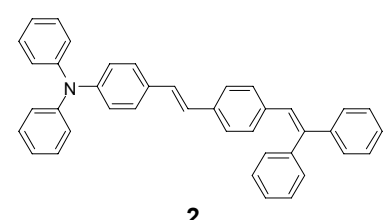

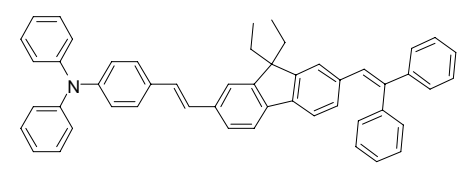

5

Scheme 1. Structures of newly designed styrylamine derivatives 

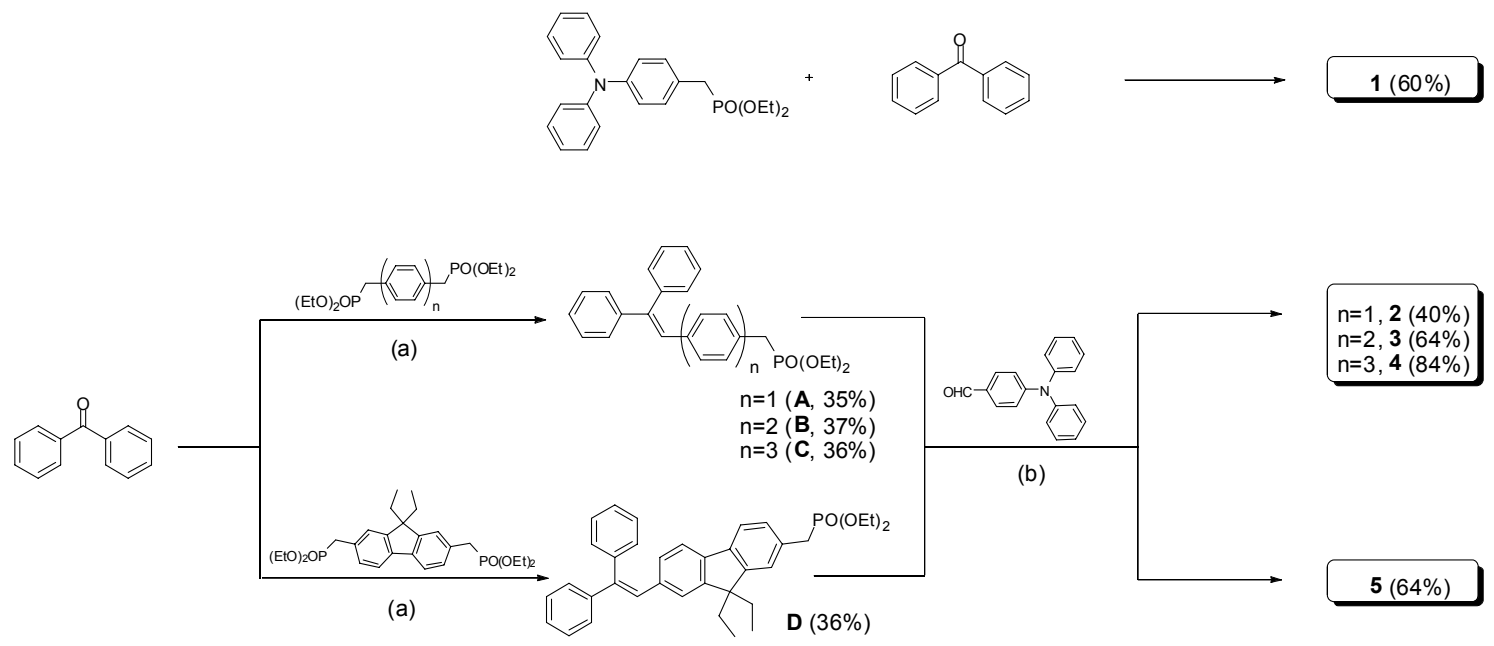

Scheme 2. Synthetic routes for blue fluorescent dopants 1-5. Reagents and conditions: (a) $\mathrm{KO}^{t} \mathrm{Bu}(1.2 \mathrm{eq}), \mathrm{THF}, 0{ }^{\circ} \mathrm{C}$ to room temperature, $1 \mathrm{hr}$; (b) $\mathrm{KO}^{t} \mathrm{Bu}(1.2 \mathrm{eq}), \mathrm{THF}, 0{ }^{\circ} \mathrm{C}$ to room temperature, $2 \mathrm{hr}$. See the experimental section for full details

Table 1. Photophysical properties of Compounds 1-5

\begin{tabular}{cccccccc}
\hline Compound & $\mathrm{UV}_{\text {max }}[\mathrm{nm}]^{a}$ & $\mathrm{PL} \lambda_{\max }[\mathrm{nm}]^{b}$ & $\mathrm{FWHM}[\mathrm{nm}]$ & $\mathrm{HOMO}[\mathrm{eV}]^{c}$ & $\mathrm{LUMO}[\mathrm{eV}]^{c}$ & $\mathrm{E}_{\mathrm{g}}$ & $\Phi^{d}$ \\
\hline 1 & 365 & 472 & 85 & -5.64 & -2.56 & 3.08 & 0.01 \\
2 & 393 & 496 & 80 & -5.62 & -2.82 & 2.80 & 0.81 \\
3 & 388 & 490 & 80 & -5.58 & -2.73 & 2.85 & 0.76 \\
4 & 384 & 482 & 76 & -5.58 & -2.71 & 2.87 & 0.77 \\
5 & 399 & 482 & 76 & -5.61 & -2.79 & 2.82 & 0.91 \\
\hline
\end{tabular}

$\overline{a, b}$ Maximum absorption and emission wavelength, measured in $\mathrm{CH}_{2} \mathrm{Cl}_{2}$ solution. ${ }^{c}$ Obtained from $\mathrm{AC}-2$ and UV-vis absorption measurements. ${ }^{d}$ Using BDAVBi as a standard; $\lambda_{\mathrm{ex}}=360 \mathrm{~nm}\left(\Phi=0.86\right.$ in $\left.\mathrm{CH}_{2} \mathrm{Cl}_{2}\right)$.

(a)

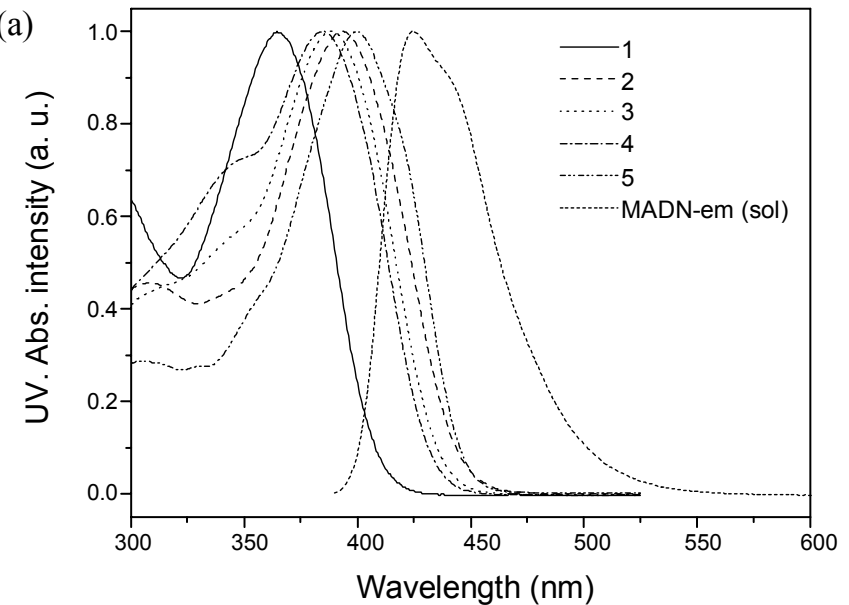

(b)

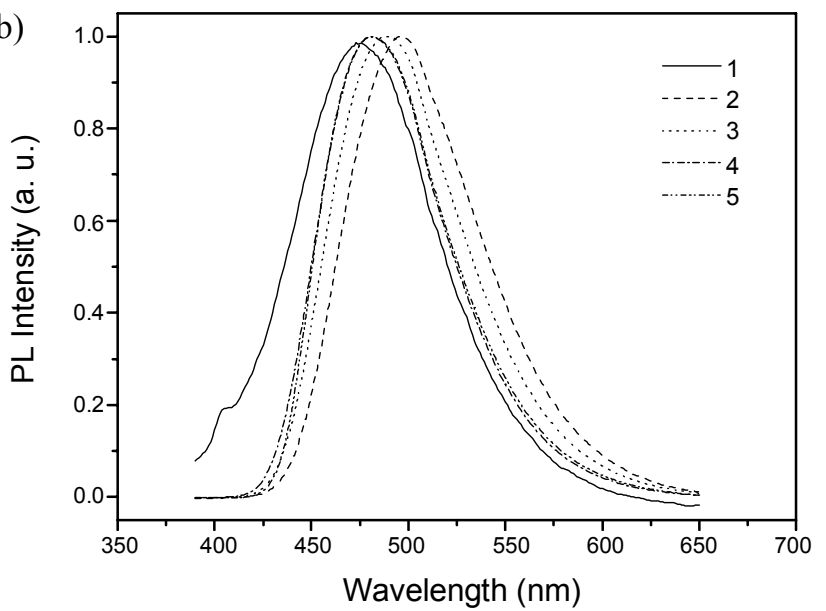

Figure 1. Normalized UV-vis absorption spectra (a) and PL spectra (b) of compounds 1-5 in dichloromethane (10 $\mu \mathrm{M})$.

solution at $25^{\circ} \mathrm{C}$ was measured using BDAVBi $(\Phi=0.86)$ as a calibration standard. The emission quantum yields of compounds 2-5 were high $(\Phi=0.76-0.91)$, suggesting that these materials are expected to have highly efficient electroluminescent properties in OLED devices.

The highest occupied molecular orbital (HOMO) and lowest unoccupied molecular orbital (LUMO) energy levels of compounds 1-5 are shown in Table 1 and Fig. 2. The HOMO/LUMO energy levels of compounds 1-5 are -5.64/-2.56, -5.62/-2.82, $-5.58 /-2.73,-5.58 /-2.71$, and $-5.61 /-2.79$, respectively. Compounds 2-5 show a slight difference between the HOMO and LUMO energy levels. It is noticeable that the LUMO level of dopant 3 and $\mathbf{4}(-2.73$ and $-2.71 \mathrm{eV})$ increased substantially in comparison with dopant $2(-2.82 \mathrm{eV})$. The distorted structure of compounds $\mathbf{3}$ and $\mathbf{4}$ lead to breaks in the conjugation along the framework and thus localized the $\pi$-electrons, making a 


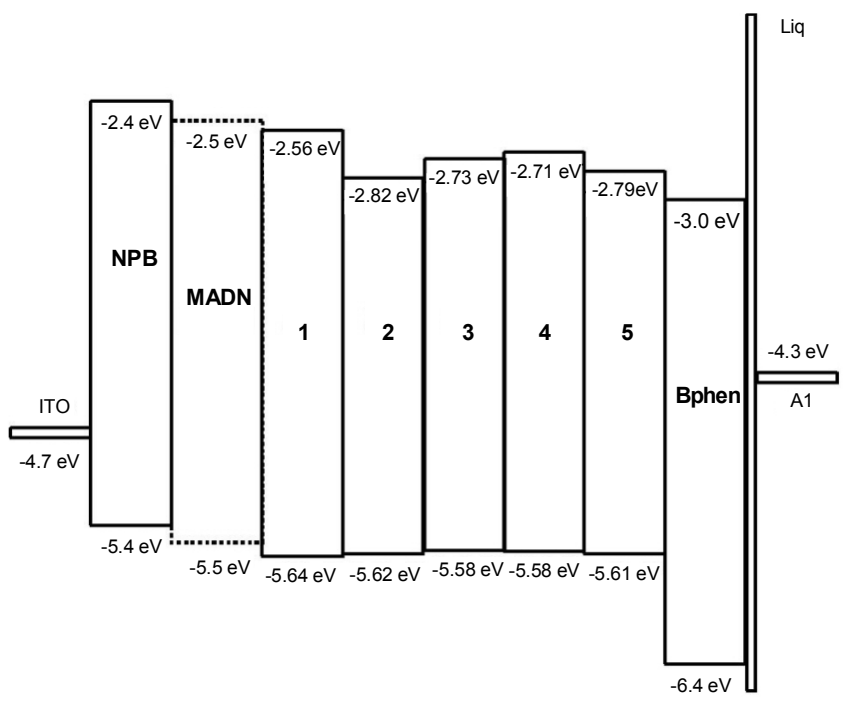

Figure 2. Energy level diagram of compounds 1-5 used in the OLED fabrication.

larger energy gap relative to compound $\mathbf{2}$.

In order to understand the observed properties of materials for organic light emitting diodes at the molecular level, we carried out the density functional theory (DFT) calculations for $\mathbf{3}$ and $\mathbf{5}$ using the nonlocal density functional of Becke's three parameters employing Lee-Yang-Parr functional (B3LYP) with $6-31 \mathrm{G}^{*}$ basis sets using a suite of Gaussian 03 programs. ${ }^{16}$ For 3, the dihedral angles between phenyl (linked with diphenylamino group) and phenyl (linked with styryl group) calculated to be 4.92 . For $\mathbf{5}$, the dihedral angles between phenyl (linked with diphenylamino group) and fluorene (linked with styryl group) calculated to be 10.86 . The geometry structure and distributions of HOMOs and LUMOs for $\mathbf{3}$ and $\mathbf{5}$ were shown in Fig. 2. The HOMOs and LUMOs for $\mathbf{3}$ and $\mathbf{5}$ were quite similar to each other.

To investigate the transition energies and properties for $\mathbf{3}$ and $\mathbf{5}$, we carried out the single point-TDDFT calculations from ground state geometry structure. It was found that transition energies with highest oscillation strength were 2.85 and $2.82 \mathrm{eV}$, respectively, and these values were corresponded to the absorp- tion wavelength of 388 and $399 \mathrm{~nm}$, respectively. From the highest oscillation strength, transition property of $\mathbf{3}$ and $\mathbf{5}$ is HOMO to LUMO transition. Our theoretical results for $\mathbf{3}$ and 5 are in good agreement with experimental results.

To explore the electroluminescent properties of these molecules, devices were fabricated with a structure of indium tin oxide (ITO)/NPB (500 $\AA$ )/MADN: Blue dopants 1-5 (300 $\AA$ )/ Bphen $(300 \AA) / \operatorname{Liq}(20 \AA) / \mathrm{Al}(1000 \AA)$ and their electroluminescent properties summarized in Table 2 . The doping concentrations of 1-5 in MADN were optimized to $10 \%$, respectively. The EL emission spectra of the devices 1-5 with emitting layers consisting of the MADN host doped with dopants 1-5 are seen in Fig. 4. All devices exhibited blue emissions with maximum emission peaks between 451 - $468 \mathrm{~nm}$. The EL emission spectra of devices 1-5 exhibited blue-shifted emission by ca. $20-30 \mathrm{~nm}$ as compared to the photoluminescence spectra of dopants 1-5 in the solution state. These blue-shifts in the emission maxima are presumably due to differences in solvation states in the different environments such as solution and thin film device.

The contribution of the host MADN to the EL emission can be excluded given the superior EL performances of devices 2-5 relative to that of a similar device using only MADN as the emitting layer, thus demonstrating light emissions from dopants 2-5 through the efficient Foster type energy transfer between MADN and dopants. In device 1, the energy transfer from MADN host to dopant $\mathbf{1}$ is not efficient because of the wider band-gap of dopant 1 than those of MADN. However, the more efficient EL performances of device 1 than MADN-only device and the differences in the EL spectra between device 1 and MADN-only device suggest the contribution of dopant 1 to EL emission of device 1. These results can be explained by the endothermic energy transfer from MADN host to dopant 1 . $^{17}$ In this system, the confinement of excitons in dopant is inefficient due to the smaller band-gap energy of host than dopant. Thus device 1 exhibited not only an emission of dopant 1 but also MADN host. Also, compared to devices 2-5 in which are possible the exothermic energy transfer systems, the EL performances of device 1 are decreased because of the interferences of the low efficient MADN emissions. In addition, the contribution of the exciplexes ${ }^{18}$ between MADN host and do-

Compound HOMO LUMO

Figure 3. The B3LYP/6-31G* calculated HOMOs and LUMOs for 3 and $\mathbf{5}$. 
Table 2. EL performance characteristic of Devices 1-5

\begin{tabular}{ccccccc}
\hline Device & $\mathrm{EL}_{\max }[\mathrm{nm}]$ & $\mathrm{L}\left[\mathrm{cd} / \mathrm{m}^{2}\right]^{a}$ & L.E. $[\mathrm{cd} / \mathrm{A}]^{b}$ & P.E. $[\mathrm{lm} / \mathrm{W}]^{b}$ & ${\text { E.Q.E. }[\%]^{b}}$ & ${\mathrm{CIE}(\mathrm{x}, \mathrm{y})^{c}}$ \\
\hline 1 & 451 & 6260 & 3.30 & 2.10 & 2.61 & $(0.161,0.217)$ \\
2 & 468 & 31700 & 10.4 & 6.30 & 6.62 & $(0.184,0.346)$ \\
3 & 459 & 29300 & 11.1 & 7.30 & 7.55 & $(0.161,0.265)$ \\
4 & 455 & 26800 & 9.80 & 6.40 & 6.70 & $(0.157,0.237)$ \\
5 & 462 & 24000 & 12.5 & 6.50 & 6.81 & $(0.173,0.306)$ \\
MADN only & 442 & 954 & 1.08 & 0.480 & 1.10 & $(0.153,0.080)$
\end{tabular}

${ }^{a}$ The luminance at $11.0 \mathrm{~V},{ }^{b}$ At $20 \mathrm{~mA} / \mathrm{cm}^{2},{ }^{c}$ Commission Internationale d'Énclairage (CIE) coordinates at a $8.0 \mathrm{~V}$

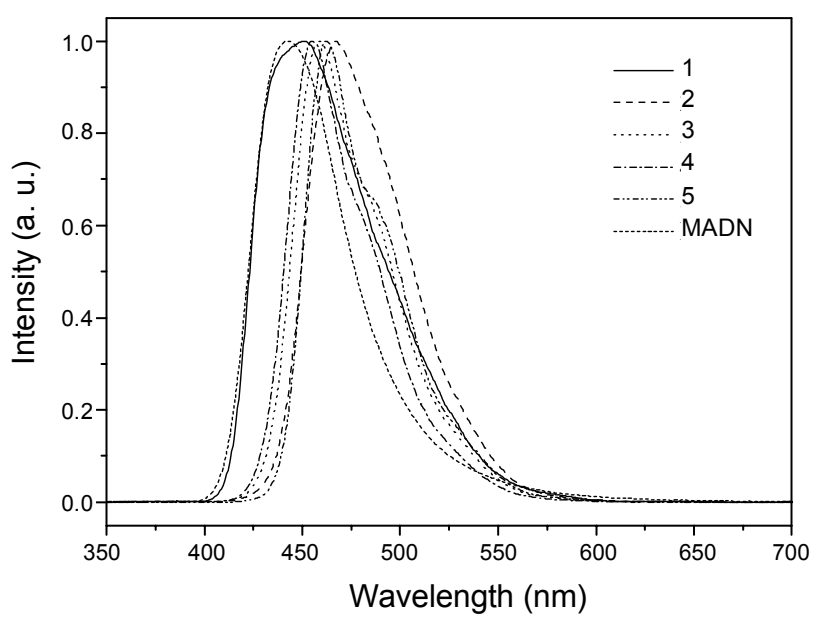

Figure 4. EL spectra of blue emitting devices with the structure ITO/ NPB/MADN: compounds 1-5/Bphen/Liq/Al.

pant to emissions of device $\mathbf{1}$ cannot be excluded. As pointed by Thompson and Adachi, ${ }^{19}$ the exciplex between host and dopant 1 can exist in similar energy state to host and dopant and play significant roles in emissions of OLEDs. This notion can be applied to the explanation of the EL performances of device 1. Particularly, in EL spectra of device 1, there is the additional maximum peak of emission at $451 \mathrm{~nm}$, as shown in Fig. 4. This observation suggests the exciplex formation of MADN with dopant 1.

The corresponding CIE coordinates at $8.0 \mathrm{~V}$ were $(0.161$, $0.217)$ for device $1,(0.184,0.346)$ for device $2,(0.161,0.265)$ for device $3,(0.157,0.237)$ for device 4 , and $(0.173,0.306)$ for device 5, respectively. Compared to CIE coordinates of device 1, those of 2-5 show small red-shifts from 0.048 to 0.129 in the $\mathrm{CIE}_{y}$ coordinate due to the lengthening $\pi$-conjugation length of the dopants.

The luminance-voltage $(L-V)$ and current density-voltage $(J-V)$ characteristics of the five devices are shown in Fig. 5a and $\mathrm{b}$, respectively. The maximum brightness of these blue OLEDs varied from $6260 \mathrm{~cd} / \mathrm{m}^{2}$ in device 1 to as high as $31700 \mathrm{~cd} / \mathrm{m}^{2}$ in device 2. The current density of devices $\mathbf{1 - 5}$ is determined by several factors such as the difference of the HOMO/LUMO energy levels between the adjacent organic layers and the charge carrier mobility of each organic compound. Since materials and structures in devices 1-5 are identical except dopants, the HO$\mathrm{MO} / \mathrm{LUMO}$ energy levels and the charge carrier mobilities of dopants seems to be profound effects on electric properties of
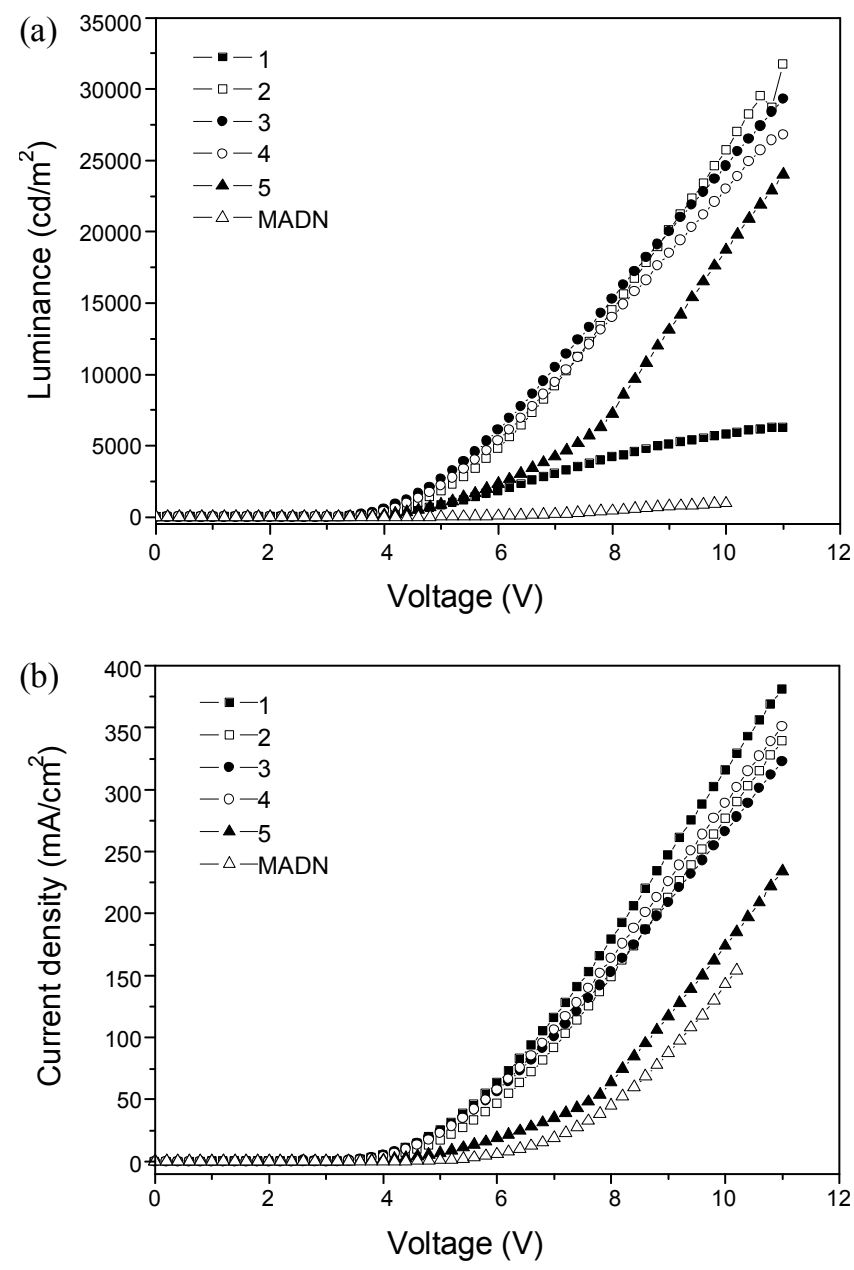

Figure 5. $L-V$ characteristics (a) and $J-V$ characteristics (b) of the devices 1-5.

devices. In the case studied herein, HOMOs of five blue emitters are slightly different, the biggest difference among compounds 1-5 is only $0.06 \mathrm{eV}$. The variation of LUMOs of the five blue materials is not negligible and the variation can be as high as $0.26 \mathrm{eV}$. However, the current densities of devices are not well correlated with the variation of LUMOs energy levels of dopants in the corresponding devices. These observations suggest that the magnitude of current density of devices 1-5 clearly not follows the order of HOMO/LUMO energy levels of five blue emitters. Presumably, the charge carrier mobility of blue lightemitting materials 1-5 becomes the key factor in determining 
(a)

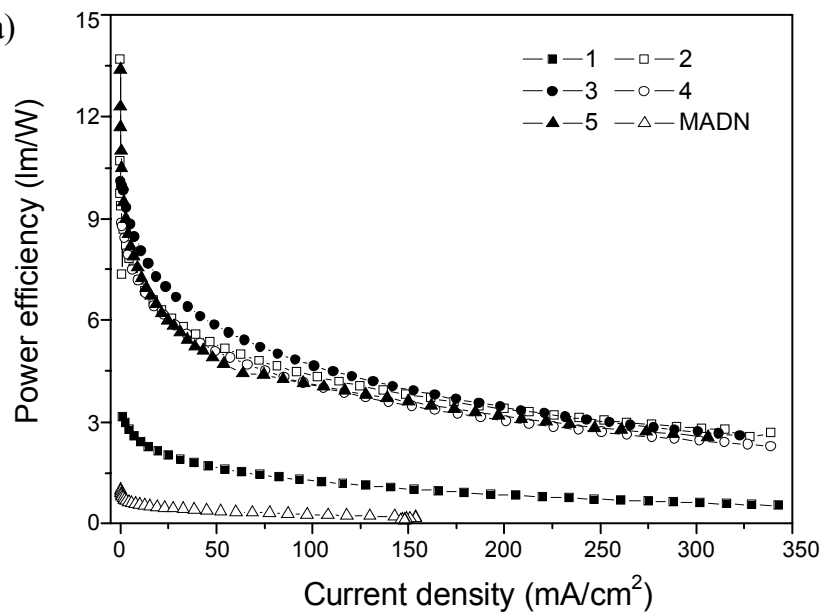

(b)

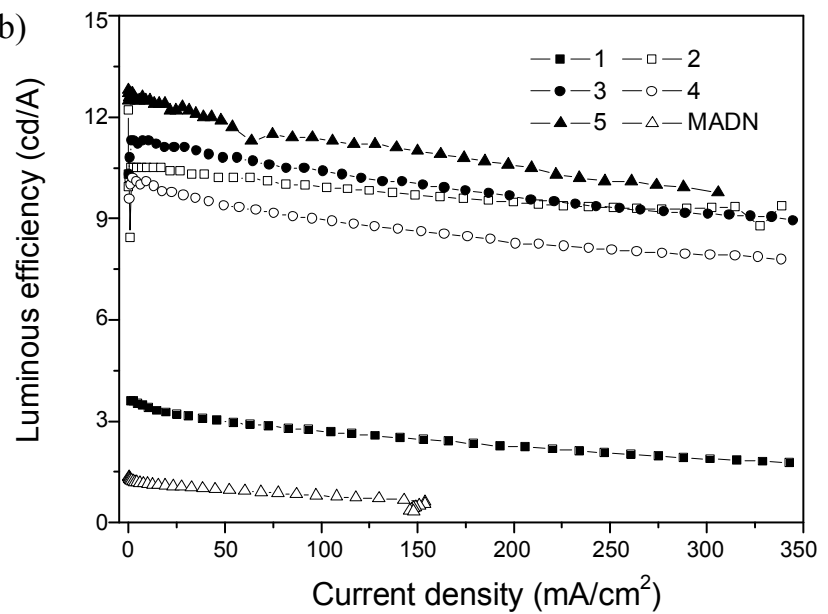

Figure 6. (a) Power efficiencies and (b) luminous efficiencies as a function of current density for the devices 1-5.

current density of these devices.

Variations in the luminous and power efficiencies of devices 1-5, as a function of the current density are shown in Fig. 6a and b. The luminous efficiency of devices $\mathbf{1 - 5}$ were $3.3,10.4,11.1$, 9.8 , and $12.5 \mathrm{~cd} / \mathrm{A}$ at $20 \mathrm{~mA} / \mathrm{cm}^{2}$, respectively. The power efficiency of devices $1-5$ were $2.1,6.3,7.3,6.4$, and $6.5 \mathrm{~lm} / \mathrm{W}$ at 20 $\mathrm{mA} / \mathrm{cm}^{2}$, respectively. Notably, the efficiencies of the OLED devices of 2-5 were much higher than that of 1 due to the well matched spectral overlap between the emission of the host and the absorption of the dopants shown in Fig. 1. This clearly suggests that the efficient energy transfer between host and dopant plays an important role in OLED efficiency. The luminous and power efficiencies were very sensitive to the structure of the spacer group of the dopants in the emitting layer. For example, compared to device 4, the luminous efficiencies of devices $\mathbf{2}$, 3 , and 5 increased by $6.12,13.3$, and $27.6 \%$, respectively. Thus, a device with a 2,7-fluorenyl spacer group in the dopant showed the best luminous efficiency. In the majority of cases, blue OLED with a larger $\mathrm{CIE}_{y}$ value often performs better than that with a smaller $\mathrm{CIE}_{y}$ value. However, high-performance device $\mathbf{5}$ is not simply a matter of color purity because the performance of device 2 with $\mathrm{CIE}_{y}=0.346$ is not much better than that of device 5 with $\mathrm{CIE}_{y}=0.306$. Compound $\mathbf{5}$ in device $\mathbf{5}$ has $\Phi_{\mathrm{f}}=0.91$ in the solution state, which is higher than $\Phi_{\mathrm{f}}=0.81$ of compound 2 in device 2. Presumably, the higher fluorescent quantum yield of dopant $\mathbf{5}$ over dopant $\mathbf{2}$ would contribute to the improved EL efficiency of device 5. This highly efficient sky blue-emitting dopant could thus be used in the WOLED. Although white emission in OLED can be achieved by a mixture of the three primary colors (red, green, blue), highly efficient WOLEDs by fabrication of two complementary colors have been demonstrated. ${ }^{20,21}$ Thereby, the highly efficient sky blue-emitting dopant 5 can be combined with suitable orange-emitting materials to fabricate efficient WOLEDs.

\section{Conclusions}

A series of styrylamine derivatives end-capped with a diphenylvinyl group as dopant materials in blue OLEDs have been synthesized and characterized. In an OLED employing the new- ly designed dopant 5 with MADN as the host, the maximum luminance was $24,000 \mathrm{~cd} / \mathrm{m}^{2}$ at $11.0 \mathrm{~V}$. The luminous and power efficiencies were $12.5 \mathrm{~cd} / \mathrm{A}$ and $6.5 \mathrm{~lm} / \mathrm{W}$ at $20 \mathrm{~mA} / \mathrm{cm}^{2}$, respectively. The CIE coordinates were $(\mathrm{x}=0.173, \mathrm{y}=0.306)$ at $8.0 \mathrm{~V}$. This study clearly suggests that styrylamine derivatives endcapped with a diphenylvinyl group possess excellent properties for blue-emitting materials for OLEDs.

Acknowledgments. This work was supported by a grant 20090073679 from Korea Science and Engineering Foundation.

\section{References}

1. Tang, C. W.; VanSlyke, S. A. Appl. Phys. Lett. 1987, 51, 913.

2. Friend, R. H.; Gymer, R. W.; Holmes, A. B.; Burroughes, J. H.; Marks, R. N.; Taliani, C.; Bradley, D. D. C.; Dos Santos, D. A.; Bredas, J. L.; Logdlund, M.; Salaneck, W. R. Nature 1999, 397, 121.

3. Forrest, S. R. Org. Electron. 2003, 4, 45.

4. Danel, K.; Huang, T. H.; Lin, J. T.; Tao, Y. T.; Chuen, C. H. Chem. Mater. 2002, 14, 3860.

5. Tang, C.; Liu, F.; Xia, Y. L.; Lin, J.; Xie, L. H.; Zhong, G. Y.; Fan, Q. L.; Huang, W. Org. Electron. 2006, 7, 155.

6. Tang, C.; Liu, F.; Xia, Y. L.; Lin, J.; Xie, L. H.; Huang, W.; Li, S. B.; Fan, Q. L.; Huang, W. J. Mater. Chem. 2006, 16, 4074.

7. Kauffman, J. M.; Moyna, G. J. Org. Chem. 2003, 68, 839.

8. Tang, C. W.; VanSlyke, S. A.; Chen, C. H. J. Appl. Phys. 1989, 65 , 3610 .

9. Shi, J. M.; Tang, C. W. Appl. Phys. Lett. 1997, 70, 1665.

10. Hung, L. S.; Chen, C. H. Mater. Sci. Eng. R 2002, 39, 143.

11. Shi, J. M.; Tang, C. W. Appl. Phys. Lett. 2002, 80, 3201.

12. He, F.; Tian, L.; Tian, X.; Xu, H.; Wang, Y.; Xie, W.; Hanif, M.; Xia, J.; Shen, F.; Yang, B.; Li, F.; Ma, Y.; Yang, Y.; Shen, J. Adv. Funct. Mater. 2007, 17, 1551.

13. Zheng, S.; Barlow, S.; Parker, T. C.; Marder, S. R. Tetrahedron Letters 2003, 44, 7989.

14. Li, C. L.; Shieh, S. J.; Lin, S. C.; Liu, R. S. Org. Lett. 2003, 5, 1131.

15. Plater, M. J.; Jackson, T. Tetrahedron 2003, 59, 4673.

16. Frisch, M. J.; Trucks, G. W.; Schlegel, H. B.; Scuseria, G. E.; Robb, M. A.; Cheeseman, J. R.; Montgomery, J. A.; Vreven, T.; Kudin, K. N.; Burant, J. C.; Millam, J. M.; Iyengar, S. S.; Tomasi, J.; Barone, V.; Mennucci, B.; Cossi, M.; Scalmani, G.; Rega, N.; Petersson, G. A.; Nakatsuji, H.; Hada, M.; Ehara, M.; Toyota, K.; Fukuda, R.; 
Hasegawa, J.; Ishida, M.; Nakajima, T.; Honda, Y.; Kitao, O.; Nakia, H.; Klene, M.; Li, S.; Knox, J. E.; Hratchian, H. P.; Cross, J. B.; Adamo, C.; Jaramillo, J.; Gomperts, R.; Stratmann, R. E.; Yazyev, O.; Austin, A. J.; Cammi, R.; Pomelli, C.; Ochterski, J. W.; Ayala, P. Y.; Morokuma, K.; Voth, G. A.; Salvador, P.; Dannenberg, J. J.; Zakrzewski, V. G.; Dapprich, S.; Daniels, A. D.; Strain, M. C.; Farkas, O.; Malick, D. K.; Rabuck, A. D.; Raghavachari, K.; Foresman, J. B.; Ortiz, J. V.; Cui, Q.; Baboul, A. G.; Clifford, S.; Cioslowski, J.; Stefanov, B. B.; Liu, G.; Liashenko, A.; Piskorz, P.; Komaromi, I.; Martin, R. L.; Fox, D. J.; Keith, T.; Al-Laham, M. A.; Peng, C. Y.; Nanayakkara, A.; Challacombe, M.; Gill, P. M. W.; Johnson, B.; Chen, W.; Wong, M. W.; Gonzalez, C.; Pople,
J. A.; Gaussian 03, revision B05, Gaussian, Inc., Pittsburgh, PA 2003.

17. Adachi, C.; Kwong, R. C.; Djurovich, P.; Adamovich, V.; Baldo, M. A.; Thompson, M. E.; Forrest, S. T. Appl. Phys. Lett. 2001, 79, 2082.

18. Berkovic, G. E.; Ludmer, Z. Chem. Phys. 1981, 58, 57.

19. Kolosov, D.; Adamovich, V.; Djurovich, P.; Thompson, M. E.; Adachi, C. J. Am. Chem. Soc. 2002, 124, 9945.

20. Sun, Y.; Giebnik, N. C.; Kanno, H.; Ma, B.; Thompson, M. E.; Forrest, R. Nature 2006, 440, 908.

21. Yook, K. S.; Jeon, S. O.; Joo, C. W.; Lee, J. Y. Appl. Phys. Lett. 2008, 93, 073302. 